\title{
Synthesis, Characterization, and Relaxivity of Two Linear Gd(DTPA)-Polymer Conjugates
}

\author{
M. G. Duarte, ${ }^{\dagger}$ M. H. Gil, ${ }^{\ddagger}$ J . A. Peters,,$^{\S}$ J . M. Colet," L. Vander Elst," R. N. Muller," and \\ C. F. G. C. Geraldes*,t,
}

Departamento de Bioquímica, Faculdade de Ciências e Tecnologia, Universidade de Coimbra, Apartado 3126, 3001-301 Coimbra, Portugal, Departamento de Engenharia Química, Faculdade de Ciências e Tecnologia, Universidade de Coimbra, Portugal, Laboratory of Applied Organic Chemistry and Catalysis, Delft University of Technology, The Netherlands, NMR Laboratory, Department of Organic Chemistry, Faculty of Medicine, University of Mons-Hainaut, B-7000 Mons, Belgium, and Centro de Neurociências de Coimbra, Portugal . Received J une 13, 2000; Revised Manuscript Received December 1, 2000

\begin{abstract}
Two linear polyamide conjugates of Gd(DTPA ${ }^{2-}$ were synthesized and characterized by high-resolution nuclear magnetic resonance (NMR) spectroscopy and size exclusion chromatography (SEC). DTPA was copolymerized with two different diamines, 1,6-hexanediamine and trans-1,4-cyclohexanediamine, yiel ding the polymers DTPA-HMD and DTPA-CHD, with low polydispersity. Their molecular flexibility in solution was studied using ${ }^{13} \mathrm{C}$ spin-lattice relaxation time measurements, indicating that the cyclohexanediamine linking moiety of the DTPA-HMD polymer is more rigid than that of DTPA$\mathrm{CHD}$. The influence of the flexibility of the linking functionalities on the relaxivity of the $\mathrm{Gd}^{3+}{ }^{+}$DTPApolymer conjugates was studied by water nuclear magnetic relaxation dispersion (NMRD). The relaxivity of the Gd(DTPA-CHD) polymer was only slightly higher than that of the Gd(DTPA-HMD) polymer, and only two times higher than the usual values for small Gd-DTPA-like chelates. The low relaxivities obtained for both polymers, much lower than expected from the polymer apparent molecular weights, result from their substantial residual flexibility, and also from a too long, nonoptimal, value of the inner-sphere water exchange rate. These polymeric compounds are also cleared very quickly from the blood of rats, indicating that they are of limited value as bl ood pool contrast agents for MRA.
\end{abstract}

\section{INTRODUCTION}

Contrast agents (CAs) for magnetic resonance imaging $(\mathrm{MRI})$ are mainly chelates of $\mathrm{Gd}^{3+}$, due to its high magnetic moment and long electronic relaxation time (1-4). A Gd(III)-bound water which exchanges with the bulk water of the body, determines via the enhancement of the relaxation ( $T_{1}$ and $T_{2}$ ) of the water protons, the intensity of the water signal and thus the contrast of the images. The relaxation theory predicts that higher relaxation rates are obtained upon increase of the rotational correlation time of the $\mathrm{Gd}^{3+}$ complexes (1-4), which may be achieved by noncovalent or covalent binding of low-molecular weight $\mathrm{Gd}^{3+}$ chelates to macromolecules or polymers $(3,4)$. These conjugates might have prolonged residence time in the cardiovascular system, with potential applications in MRI Angiography (MRA) $(5,6)$.

In fact, in the past few years there has been a great interest in the development of efficient, nontoxic, blood pool CAs for MRA examinations. For this purpose, Iow molecular weight $\mathrm{Gd}^{3+}$-chelate complexes, such as $\mathrm{Gd}$ (DTPA) ${ }^{2-}$ or Gd(DOTA ${ }^{-}$, have been conjugated to natural or synthetic polymeric materials, like polysaccharides (7-

* To whom correspondence should be addressed. E-mail: geraldes@cygnus.ci.uc.pt. Phone: 351-239-824531. Fax: 351239-853607.

† Departamento de Bioquímica.

‡ Departamento de Engenharia Química.

$\S$ Laboratory of Applied Organic Chemistry and Catalysis.

"NMR Laboratory.

$\perp$ Centro de Neurociências de Coimbra.
16), al bumin $(17,18)$, polyamino acids such as polylysine and polyornithine (19-25) or dendrimers (26). Some linear polymers of DTPA have also been prepared in which the chelate is incorporated directly in the polymeric chain (27-29). These macromolecules lead to an increase in blood pool lifetime and should be more efficient in respect to their relaxivity, as a consequence of their increased rotational correlation time resulting from their high molecular weight. However, the observed increase of their relaxivity was not as high as expected, which was attributed to a combination of two effects: the rapid internal rotational motion of the linking moieties between the $\mathrm{Gd}^{3+}$-chelate in the pol ymeric chain and too long inner-sphere water exchange rates. The fact that dendrimer-based contrast agents show higher relaxivities compared to other systems confirms that more rigid structures lead to more efficient macromolecular contrast agents (26).

Here we report the synthesis, physicochemical characterization and in vivo pharmacokinetics in Wistar rats of two linear polyamide conjugates of Gd(III)-DTPA, Gd(DTPA-HMD), and Gd(DTPA-CHD) (seetheir structures in Figure 1), obtained by copolymerization of DTPA with two different diamines, the linear and conformationally flexible 1,6-hexanediamine and the cyclic and conformationally more rigid trans-1,4-cyclohexadiamine. The influence of the molecular flexibility of the respective functionalities on the relaxivity of the Gd(III)-DTPApolymer conjugates is also reported and compared with other systems from the literature. As macromolecular polyamides, they should be biodegradable and biocom- 


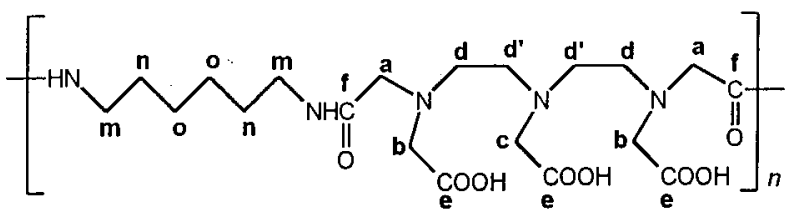

(a)

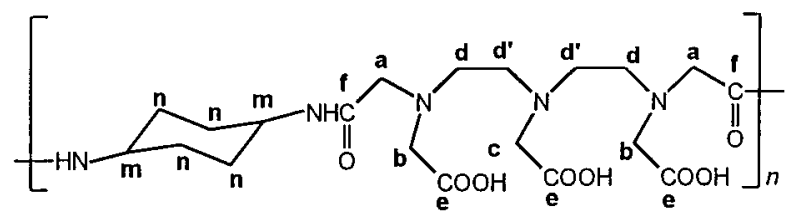

(b)

Figure 1. Structure of the repeating unit of the DTPA linear polymers: (a) DTPA-HMD; (b) DTPA-CHD.

patible, and their $\mathrm{Gd}^{3+}$ complexes should in principle be promising as NMR angiography (MRA) contrast agents.

\section{EXPERIMENTAL PROCEDURES}

Reagents. Diethylenetriamine pentaacetic acid (DTPA) $97 \%$ purity, $\mathrm{GdCl}_{3} \cdot 6 \mathrm{H}_{2} \mathrm{O}$, trans-1,4-cycl ohexanediamine (CHD) and 1,6-hexanediamine (HMD) were purchased from Aldrich and used as supplied. Acetic anhydride, pyridine and dimethyl sulfoxide, al so from Aldrich, were dried over $3 \AA$ molecular sieves before use.

Synthesis and Characterization of DTPA Copolymers and $\mathbf{G d}^{3+}$ Conjugates. Preparation of DTPA-bisAnhydride (DTPA-BA). A modification of procedure described in the literature $(28,30)$ was applied: $0.125 \mathrm{~mol}$ of DTPA was mixed with 0.558 mol of dried acetic anhydride and $0.770 \mathrm{~mol}$ of dried pyridine. The resulting suspension was stirred for $24 \mathrm{~h}$ at $65^{\circ} \mathrm{C}$. Then the solid obtained was filtered, washed with dried diethyleter and dried under vacuum, until constant weight at $25^{\circ} \mathrm{C}$. The DTPA-bis-anhydride was characterized by NMR. ${ }^{1} \mathrm{H}$ NMR (DMSO- $\left.\mathrm{d}_{6}\right) \delta(\mathrm{ppm}) 3.7(\mathrm{~s}, 8 \mathrm{H}), 3.29(\mathrm{~s}, 2 \mathrm{H}), 2.43$ $(\mathrm{t}, 4 \mathrm{H}), 2.58(\mathrm{t}, 4 \mathrm{H}) ;{ }^{13} \mathrm{C}$ NMR (DMSO- $\left.\mathrm{d}_{6}\right) \delta$ (ppm) 171.9, $165.7,54.5,52.5,51.7,50.7$. This product was considered sufficiently pure to be used in the preparation of the polymers.

Polymerization of DTPA-BA with HMD. In a roundbottom flask, $6 \mathrm{mmol}$ of DTPA-BA were dissolved in 30 $\mathrm{mL}$ of DMSO and an equimolar amount of HMD was added. The mixture was heated at $70{ }^{\circ} \mathrm{C}$ under $\mathrm{N}_{2}$ bubbling. Over a period of $3 \mathrm{~h}$ a large part of the solvent was sl owly distilled under $\mathrm{N}_{2}$ at reduced pressure $\left(70^{\circ} \mathrm{C}\right)$. The product was precipitated in acetone, filtered, and dissolved in $20 \mathrm{~mL}$ of distilled water. The solution was dialyzed for 3 days, using a MWCO 12-14000 Membrane purchased from Medicel, London, U.K., and Iyophilized to give $0.33 \mathrm{~g}$ of polymer (11.6\%).

Polymerization of DTPA-BA with CHD. The same procedure as described above was followed except that $5.6 \mathrm{mmol}$ of DTPA-BA and of CHD were used. After lyophilisation, $0.63 \mathrm{~g}$ of polymer was obtained (24\%).

Preparation of the $\mathrm{Gd}^{3+}$ Conjugates. The polymers were dissolved in a small amount of distilled water and equimolar amounts of an aqueous solution of $\mathrm{GdCl}_{3}$ were added dropwise with stirring, for the period of $1 \mathrm{~h}$. The $\mathrm{pH}$ was maintained at 5.8 by the addition of $0.1 \mathrm{M} \mathrm{NaOH}$. The solutions were dialyzed until no free $\mathrm{Gd}^{3+}$ was detected, using xylenol-orange as indicator. The samples were then Iyophilized.

Determination of $\mathrm{Gd}^{3+}$. The metal content (\%) in the polymer conjugates was determined by inductively coupled plasma optical emission spectroscopy (ICP-OES), using a J obin Yvon-J y 70 Plus spectrometer.

The metal binding to the polymers was al so determined by titration of aqueous solutions $\left(\mathrm{D}_{2} \mathrm{O}\right)$ of those polymers with solid aliquots of $\mathrm{GdCl}_{3}$ while maintaining neutral $\mathrm{pH}$ by addition of aqueous $\mathrm{NaOH}$. The formation of the complex was monitored by measuring the shift of the ${ }^{17} \mathrm{O}$ NMR signal of water at $348 \mathrm{~K}(2,16)$. The presence of unbound $\mathrm{Gd}^{3+}$ was readily detected by a dramatic increase in the chemical shift and width of the signal. Then, evaluation of the titration data allowed for determination of the percent of DTPA binding moieties of the polymer complexed to $\mathrm{Gd}^{3+}$.

NMR Measurements. ${ }^{1 \mathrm{H}}$ (499.824 MHz), ${ }^{13} \mathrm{C}$ (125.697 $\mathrm{MHz})$, and ${ }^{17} \mathrm{O}(67.760 \mathrm{MHz}) \mathrm{NMR}$ spectra were recorded on a Varian Unity 500 spectrometer (at an external field of $11.8 \mathrm{~T}$ ) in $\mathrm{D}_{2} \mathrm{O}(99.8 \% \mathrm{D}$ from Sigma Chem. Co.) solutions. For the ${ }^{1} \mathrm{H}$ NMR spectra, the water signal was used as internal reference, set at $\delta 4.75 \mathrm{ppm}$ (at $298 \mathrm{~K}$ ) and was suppressed by a presaturation pulse. ${ }^{13} \mathrm{C}$ NMR spectra were measured with broad-band proton decoupling, using the methyl resonance of TSP (sodium-3trimethylsilylpropionate-2,2-3,3- $\mathrm{d}_{4}$ ) as internal reference, set at $\delta=0 \mathrm{ppm} .{ }^{13} \mathrm{C}$ NMR spin-lattice relaxation time $\left(T_{1}\right)$ values were measured using the inversionrecovery technique. Assignments of the ${ }^{1} \mathrm{H}$ and ${ }^{13} \mathrm{C} N M R$ spectra were based on literature data for similar systems $(28,31)$ and on the results of two-dimensional homonuclear correlation spectra (COSY). The $\mathrm{pH}$ of the solutions was adjusted with $\mathrm{DCl}$ and $\mathrm{CO}_{2}$-free $\mathrm{NaOD}$ (from Sigma Chem. Co.) using a Crison MicropH 2002 $\mathrm{pH}$-meter with an I ngol d 405-M5 combined electrode. The temperature precision of the experiments was $\pm 0.5^{\circ} \mathrm{C}$.

SEC Measurements. The apparent molecular weights of the polymers were determined by size-exclusion chromatography (SEC) using two series of PI-Aquagel-OH30 columns (from Polymer Laboratories) coupled to a LC$25 \mathrm{RI}$ detector. The eluent was $0.2 \mathrm{M} \mathrm{NaCl}$. Systematic errors in the molecular weight determinations, leading to apparent values result from the charges of the polymers. The weight-average molecular weight $\left(M_{w}\right)$ and number-average molecular weight $\left(\mathrm{M}_{\mathrm{n}}\right)$ of the polymers are given by the expressions $\mathrm{M}_{\mathrm{w}}=\left(\mathrm{SN}_{\mathrm{i}} \mathrm{M}_{\mathrm{i}}{ }^{2}\right) /\left(\mathrm{SN}_{\mathrm{i}} \mathrm{M}_{\mathrm{i}}\right)$ and $\mathrm{M}_{\mathrm{n}}=\left(S \mathrm{~N}_{\mathrm{i}} \mathrm{M}_{\mathrm{i}}\right) /\left(S N_{\mathrm{i}}\right)$, where $\mathrm{N}_{\mathrm{i}}$ is the number of molecules of molecular weight $\mathrm{M}_{\mathrm{i}} . \mathrm{M}_{\mathrm{w}}$ and $\mathrm{M}_{\mathrm{n}}$ were calculated using a calibration curve of poly(ethylene glycol) standards obtained using a software program, EzChrom Chromatography V6.6, Scientific Software, Inc. The $M_{w} / M_{n}$ ratio, named polydispersity, which is a measure of the width of the molecular weight distribution, was also calculated.

Relaxometry Studies. The chelates were dissolved in ultrapure $\mathrm{H}_{2} \mathrm{O}$ and the water $\mathrm{T}_{1}$ relaxation times of the solutions were measured at $9 \mathrm{MHz}$ and $298 \mathrm{~K}$ using an MRS-4 relaxometer (J ozef Stefan Institute, Ljubliana, Slovenia), using an inversion recovery pulse sequence $\left(180^{\circ}\right.$-t- $\left.90^{\circ}\right)$ with eight delay times. The relaxivity was determined by calculating the slope of the curve of relaxation rate $\left(1 / \mathrm{T}_{1}\right)$ versus $\mathrm{Gd}^{3+}$ concentration (mmol/ L).

Proton nuclear magnetic relaxation dispersion (NMRD) profiles were recorded at $310 \mathrm{~K}$ on a field cycling relaxometer (Field Cycling Systems, Honesdale, PA) working between 0.02 and $50 \mathrm{MHz}$. Additional points at 60 and $300 \mathrm{MHz}$ were obtained on a Bruker Minispec mq60 (Bruker, Karlsruhe, Germany) and on a Bruker AMX 300 spectrometer (Bruker, Karlsruhe, Germany). Fitting of the ${ }^{1} \mathrm{H}$ NMRD curves was performed with a previously described software using minimization routines (Minuit, CERN Library) $(32,33)$. 


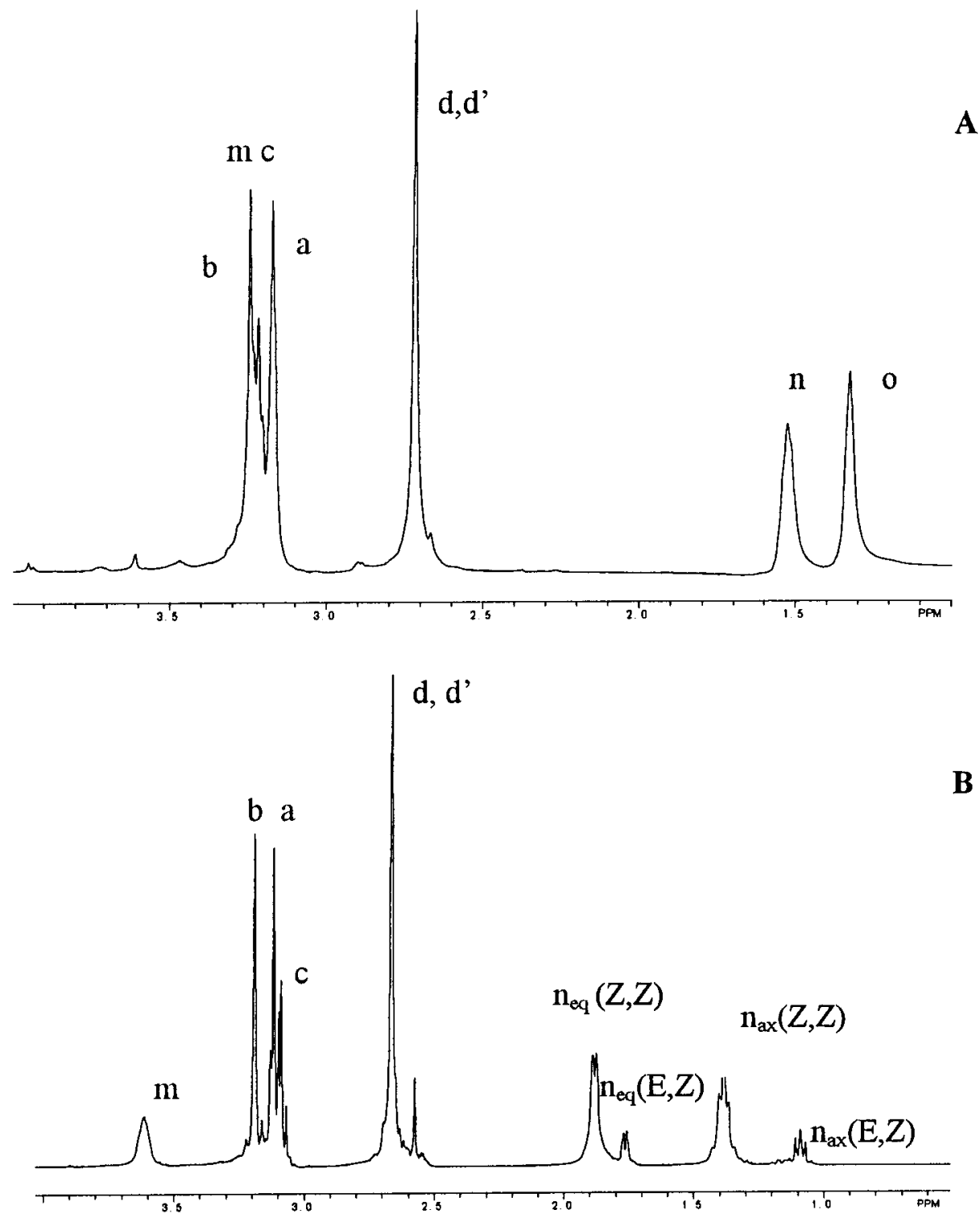

Figure 2. ${ }^{1} \mathrm{H}$ NMR spectra of the copolymers: (A) DTPA-HMD polymer obtained in $\mathrm{D}_{2} \mathrm{O}+\mathrm{NaOD}(57,2 \mathrm{mg} / \mathrm{mL})$ at $25^{\circ} \mathrm{C}, \mathrm{pH} 10.71$; (B) DTPA-CHD polymer obtained in $\mathrm{D}_{2} \mathrm{O}+\mathrm{NaOD}(41.6 \mathrm{mg} / \mathrm{mL})$ at $25^{\circ} \mathrm{C}, \mathrm{pH} 11.2$

Pharmacokinetics. The pharmacokinetic studies were carried out according to the foll lowing protocol: the Wistar rats were anesthetized by i.p. injection of Nembutal (100 $\mu \mathrm{L} / 100 \mathrm{~g}$ b.w.), the carotid artery was catheterized for rapid blood collection, $200 \mu \mathrm{L}$ of contrast agent were injected in the blood through the femoral vein; blood samples ( $\pm 300 \mu \mathrm{L} /$ sample) were collected $1,2,5,10,15$, 30,45 , and $60 \mathrm{~min}$. afterward; the longitudinal relaxation rate $\mathrm{R}_{1}$ was measured at $39^{\circ} \mathrm{C}$ on a spin analyzer PC120 (Bruker, Rheinstetten, Germany) on each sample.

\section{RESULTS AND DISCUSSION}

The copolymers of DTPA obtained were synthesized by an easy method that leads to polyamides. After purificati on, these polymers were found to be water soluble. The structure of both polymers is represented in Figure 1. Their ${ }^{1} \mathrm{H}$ NMR spectra, shown in Figure 2, have narrow peaks suggesting that the polymers present are rather flexible. The assignments of the ${ }^{1} \mathrm{H}$ signals were based on their intensities, multiplicities and chemical shifts, and confirmed by ${ }^{1} \mathrm{H}$-COSY spectra. The assignments of the methylene protons of the DTPA moiety were obtained from the previously described proton NMR titration curves of DTPA derivatives (31). In spectrum B, we can observe the polymeric species corresponding to two conformations. The substitution groups in cyclohexane are mainly in diequatorial configuration because of the effect of 1,3-diaxial interactions. However, due to the partial double bond character of the amide $\mathrm{N}-\mathrm{C}$ bonds, the repeated unit in the polymer can be in three conformations, which are E,Z, E,E, and Z,Z (Figure 3). Only two sets of signals, with intensity ratios 4.9:1, were observed in the ${ }^{1} \mathrm{H}$ NMR spectrum. An inspection of molecular models suggests that the steric strain in the three possible configurations of the disubstituted cyclohexane moieties follows the order $E, E>E, Z>Z, Z$. Therefore, we assign the two sets of signals to the $E, Z$ and $Z, Z$ configurations, and we assume that the population of the $E, E$ configuration is negligible. In the DTPAHMD polymer only a single set of broad signals was observed, which can be explained by the fast exchange between the isomers on the NMR time scale.

Figure 4 shows the proton decoupled ${ }^{13} \mathrm{C}$ N MR spectra of the two polymers, which were assigned on the basis of the $\mathrm{pH}$ dependence of their chemical shifts and previous work on small DTPA-bisamides (34). F or the DTPA-CHD 


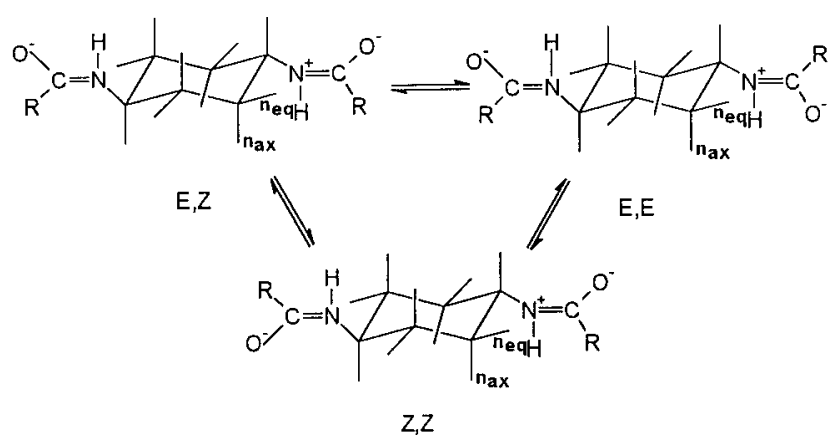

Figure 3. $E, Z, E, E$, and $Z, Z$ conformations of the trans-1,4cyclohexanediamine in the DTPA-CHD polymer.

polymer, we see two sets of resonances for carbons a-f. This is in agreement with the ${ }^{1} \mathrm{H}$ NMR data.

Table 1 shows the ${ }^{13} \mathrm{C} \mathrm{NMR} \mathrm{T}_{1}$ values, obtained for the two polymers. These values are rather long for the ester and carboxylate carbons, due to the absence of efficient dipolar relaxation from neighboring protons. It is more instructive to compare the $\mathrm{T}_{1}$ values for the $\mathrm{CH}_{2}$ carbons, where the ${ }^{13} \mathrm{C}$ relaxation rates $\left(1 / \mathrm{T}_{1}\right)$ are proportional to an effective local rotational correlation time, which modulates the dipolar interaction between the ${ }^{13} \mathrm{C}$ and the directly bound protons, reflecting the local mobility of the molecule (35). This relationship is valid for local rotational correlation times smaller than $10^{-9} \mathrm{~s}(36)$ and can be applied to polymers that have fast internal motions. Here we see that, for both polymers, the
Table 1. ${ }^{13} \mathrm{C} \mathrm{T}_{1}$ Values (s) for the Copolymers DTPA-HMD and DTPA-CHD in $\mathrm{D}_{2} \mathrm{O}$ at $25^{\circ} \mathrm{C}$, pH 11.0

\begin{tabular}{ccc}
\hline \multirow{2}{*}{$\begin{array}{c}{ }^{13} \text { C nucleus } \\
\text { (see Figure 1) }\end{array}$} & \multicolumn{2}{c}{ polymer } \\
\cline { 2 - 3 } DTPA-HMD & DTPA-CHD \\
\hline e & $3.18 \pm 0.09$ & $2.76 \pm 0.24$ \\
a & $1.76 \pm 0.08$ & $1.49 \pm 0.13$ \\
b & $0.23 \pm 0.01$ & $0.24 \pm 0.03$ \\
c & $0.21 \pm 0.01$ & $0.20 \pm 0.04$ \\
d & $a$ & $a$ \\
d' & $0.21 \pm 0.02$ & $0.18 \pm 0.02$ \\
m & $0.20 \pm 0.01$ & $0.19 \pm 0.04$ \\
n & $0.27 \pm 0.02$ & $0.40 \pm 0.03$ \\
o & $0.30 \pm 0.02$ & $0.19 \pm 0.01$
\end{tabular}

a Not determined.

methylene carbons of the DTPA moi eties have the same mobility. This mobility is smaller than that of the linking chain for the DTPA-HMD polymer, but the same for the DTPA-CHD polymer. This surprising result may be a consequence of the slower overall tumbling rate of the second polymer, with its larger molecular weight, rather than of the local mobility of the linking moi eties. However, to correlate these data with the relaxivity of the macromolecular complexes we have to take into account the mobility of the DTPA moiety and the correlation time of the water proton.

The SEC chromatograms of our samples of the two polymers and of their $\mathrm{Gd}^{3+}$ complexes, obtained using an eluent of high ionic strenght, are shown in Figure 5. The results of their analysis (Table 2 ) show that the DTPA-

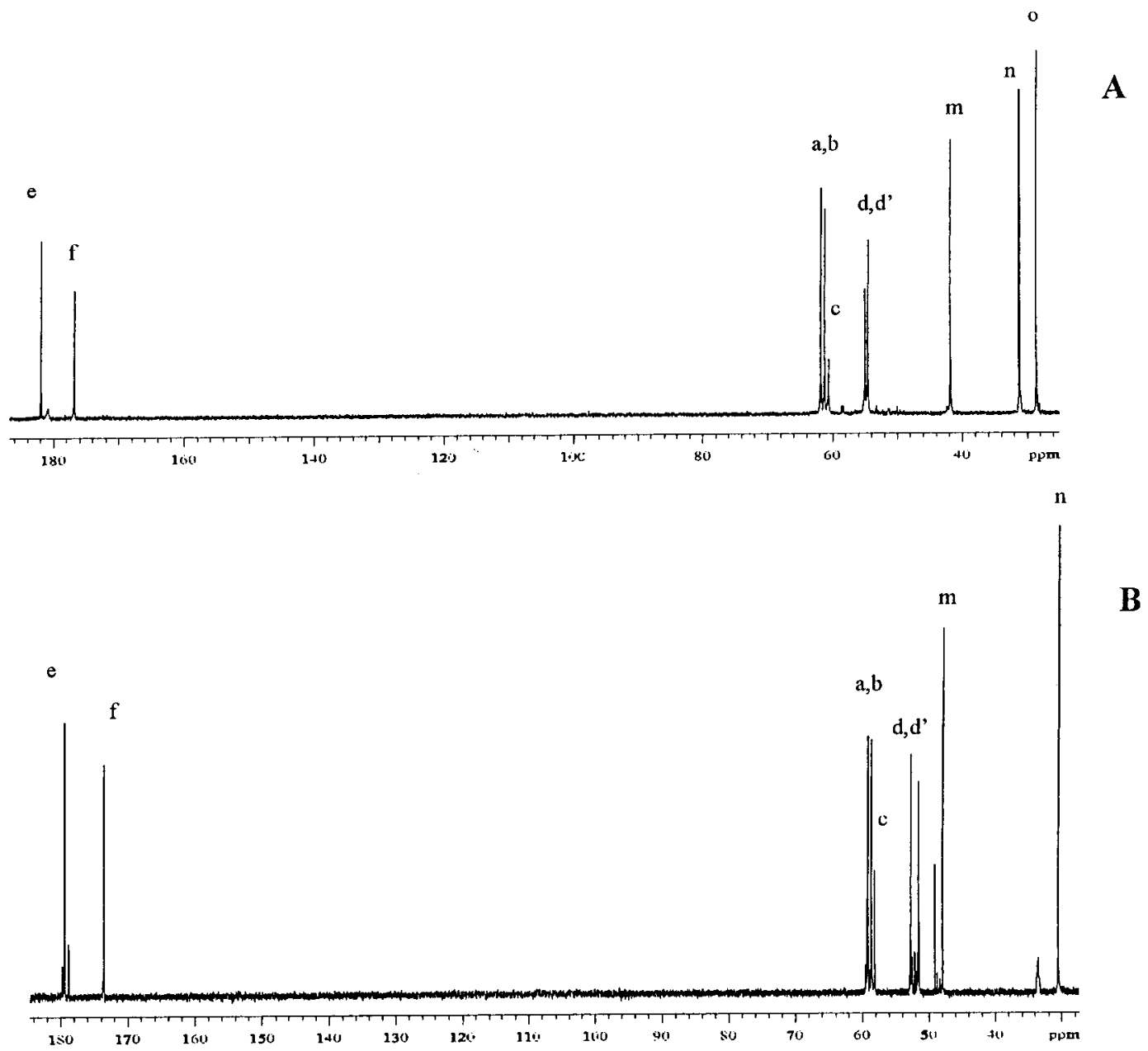

Figure 4. ${ }^{13} \mathrm{C}$ NMR spectra of the copolymers: (A) DTPA-HMD polymer obtained in $\mathrm{D}_{2} \mathrm{O}+\mathrm{NaOD}$ at $25^{\circ} \mathrm{C}, \mathrm{pH} 10.7$; $(\mathrm{B}) \mathrm{DTPA}-$ $\mathrm{CHD}$ polymer obtained in $\mathrm{D}_{2} \mathrm{O}+\mathrm{NaOD}$ at $25^{\circ} \mathrm{C}, \mathrm{pH} 11.2$. 


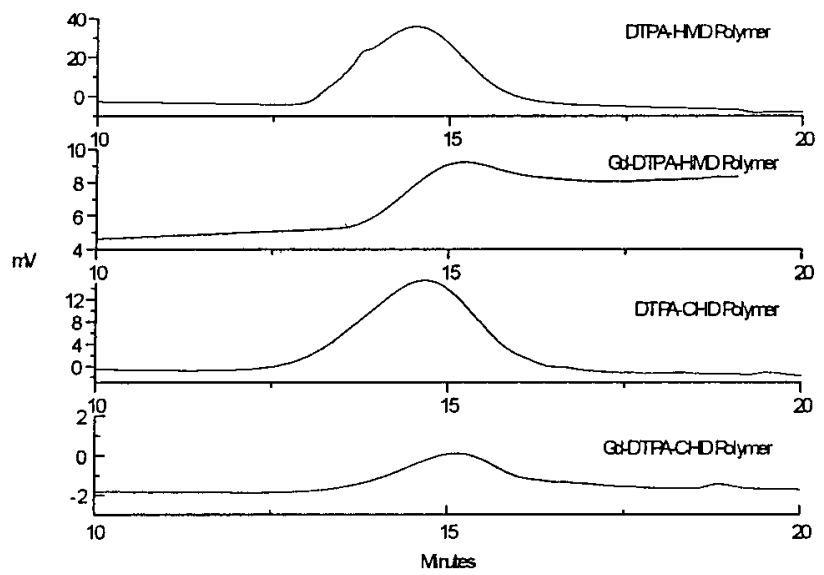

Figure 5. SEC chromatograms of the polymers DTPA-HMD and DTPA-CHD, and of the respective $\mathrm{Gd}^{3+}$ complexes.

Table 2. Comparison of the Apparent Molecular Weights of the Different Polymers Studied in this Work with Data from the Literature

\begin{tabular}{lrrcl}
\hline \multicolumn{1}{c}{ polymer } & $\mathrm{M}_{\mathrm{w}}$ & \multicolumn{1}{c}{$\mathrm{M}_{\mathrm{n}}$} & polydispersity & ref \\
\hline DTPA-HMD & 7900 & 6200 & 1.27 & $\mathrm{a}$ \\
Gd(DTPA-HMD) & 4900 & 3200 & 1.53 & $\mathrm{a}$ \\
DTPA-CHD & 8000 & 5800 & 1.37 & $\mathrm{a}$ \\
Gd(DTPA-CHD) & 6400 & 4250 & 1.50 & $\mathrm{a}$ \\
DTPA-HMD & & 2700 & & 26 \\
Gd(DTPA-HMD) & 19400 & 13300 & 1.46 & 27
\end{tabular}

a Present work.

HMD and DTPA-CHD polymers have very similar apparent molecular weights and low polydispersities, indicating that they are quite homogeneous, as we can observe in the SEC chromatograms in Figure 5. A reduction in the apparent molecular weight values of both polymers can be observed after $\mathrm{Gd}^{3+}$ complexation, and their low polydispersity slightly increases. The molecular weights of DTPA-HMD and DTPA-CHD must be lower than those of the corresponding $\mathrm{Gd}^{3+}$ complexes, due to the contribution of the cation. Thus, the observed reduction of the SEC-measured apparent values for the complexed polymers should be a result of the neutralization of charge of the DTPA polymers when bound to $\mathrm{Gd}^{3+}$. In fact, even using an high ionic strenght eluent $(0.2 \mathrm{M}$ $\mathrm{NaCl}$ ), the repulsion forces between the negatively charged polymer carboxylate groups increase the hydrodynamic volumes of the polymeric chains, leading to lower elution volumes and over-evaluated molecular weights. This is confirmed by the observation that using a low ionic strenght eluent $(0.01 \mathrm{M} \mathrm{NaCl})$, the apparent molecular weights of the of DTPA-HMD and DTPA-CHD polymers increased by a factor of 6 , while those of their $\mathrm{Gd}^{3+}$ complexes increased only by a factor of 2 (data not shown). Thus, the determination of molecular weights for this type of compounds remains a difficult problem, casting some doubt on the reliability of some of the literature data.

The $\mathrm{Gd}^{3+}$ contents in the two polymers, as measured by ICP, are shown in Table 3. Similar $\mathrm{Gd}^{3+}$ contents were measured by Kellar et al. (29) for the Gd(DTPA-HMD) polymer. The $\mathrm{Gd}^{3+}$ yields obtained show that ca. 20 and $30 \%$ of the DTPA units in Gd(DTPA-CHD) and Gd(DTPA-HMD), respectively, are uncomplexed.

The $\mathrm{Gd}^{3+}$ yields, which give the percent of DTPA binding moieties of the polymers complexed to $\mathrm{Gd}^{3+}$, were also determined by measuring the shift of the ${ }^{17} \mathrm{O} N M R$ signal of water at $348 \mathrm{~K}$ while titrating $\mathrm{D}_{2} \mathrm{O}$ solutions of those polymers with solid aliquots of $\mathrm{GdCl}_{3}$ at neutral
Table 3. $\mathbf{G d}^{3+}$ Content in the Polymer Complexes and Their Relaxivities at $9 \mathrm{MHz}$ and $298 \mathrm{~K}$

\begin{tabular}{ccccr}
\hline polymer & $\begin{array}{c}\mathrm{Gd}^{3+}(\mathrm{mol}) / \\
\text { sample }(\mathrm{g})\end{array}$ & $\begin{array}{c}\mathrm{Gd}^{3+} \text { yiel } \mathrm{d}^{\mathrm{a}} \\
(\%)\end{array}$ & $\begin{array}{c}\text { relaxivity } \\
\left(\mathrm{s}^{-1} \mathrm{mM}^{-1}\right)\end{array}$ & ref \\
\hline Gd(DTPA-CHD) & $1.7 \times 10^{-3}$ & 79 & 8.1 & $\mathrm{~b}$ \\
Gd(DTPA-HMD) & $1.4 \times 10^{-3}$ & 68 & 7.8 & $\mathrm{~b}$ \\
Gd(DTPA-HMD) & $1.4 \times 10^{-3}$ & & $9^{\mathrm{c}}$ & 27
\end{tabular}

a $\mathrm{Gd}^{3+}$ yield defined as $\left[\mathrm{Gd}^{3+}(\mathrm{mol}) /\right.$ repeating unit of polymer$(\mathrm{mol})] \times 100 .{ }^{b}$ Present work. ${ }^{\mathrm{C}}$ Estimated from NMRD curve (27).

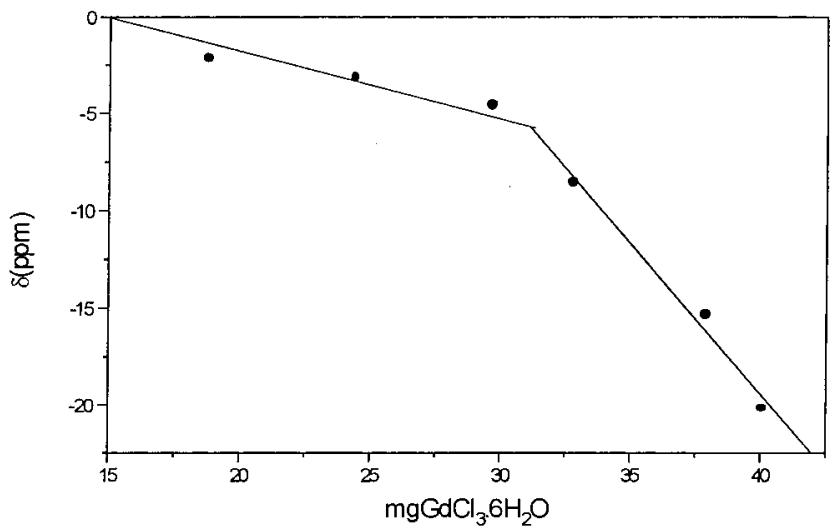

Figure 6. Plot of $\mathrm{Gd}(\mathrm{III})$ induced ${ }^{17} \mathrm{O}$ chemical shift of water (Dd) versus the amount of $\mathrm{GdCl}_{3} \cdot 6 \mathrm{H}_{2} \mathrm{O}$ added for $\mathrm{Gd}^{3+} \mathrm{com}$ plexation titration of $44.8 \mathrm{mg}$ of DTPA-CHD polymer in $0.6 \mathrm{~mL}$ of $\mathrm{D}_{2} \mathrm{O}$ at $348 \mathrm{~K}$.

$\mathrm{pH}$ (2). Figure 6 shows the plot resulting from a typical experiment with the DTPA-CHD polymer. The position of the break of the plot, indicating the presence of unbound $\mathrm{Gd}^{3+}$ gave a $\mathrm{Gd}^{3+}$ yield of $87 \%$ for the Gd(DTPA$\mathrm{CHD})$ polymer, a value in reasonably good agreement with that obtained for ICP data.

The relaxivities of the two $\mathrm{Gd}^{3+}$ polymers at $9 \mathrm{MHz}$ and $298 \mathrm{~K}$ are also shown in Table 3. The relaxivities for the polymers were less than twice the value of 5.6 $\mathrm{s}^{-1} \mathrm{mM}^{-1}$, observed for the Gd(DTPA) $)^{2-}$ chelate itself in the same conditions. The relaxivity of Gd(DTPA-HMD) is quite similar to the value reported in the literature (29). As CHD has a more rigid structure than HMD, allowing only chain-chain conformational interconversions but no single $\mathrm{C}-\mathrm{C}$ bond rotational motions, it should hinder the rotational motion of the DTPA-linking moieties in the polymeric chain. As can be seen in Table 3 , the relaxivity of the Gd(DTPA-CHD) polymer was not as high as expected, being only slightly higher than that of the Gd(DTPA-HMD) polymer. This could result from the substantial residual flexibility of that polymer, and al so from a nonoptimal value of the inner-sphere water exchange rate.

To be able to better understand the factors determining the relaxivity of these polymers, we undertook a full proton nuclear magnetic relaxation dispersion (NMRD) study of these systems. The proton NMRD profiles recorded at $310 \mathrm{~K}$ (see Figure 7) show a hump between 10 and $100 \mathrm{MHz}$ characteristic of slowly tumbling paramagnetic complexes. The analysis of the proton relaxivity takes into account the outersphere (37) and the innersphere magnetic interactions $(38,39)$. For Gd(DTPA-HMD), the values evaluated from the NMRD profiles analysis at $310 \mathrm{~K}$ for the rotational correlation time $\tau_{\mathrm{R}}$, for the el ectronic parameters ( $\tau_{\mathrm{SO}}$, the electronic relaxation time at low field, and $\tau_{\mathrm{v}}$, the correlation time modulating the electronic relaxation) and the residence time of the inner-sphere water molecule $\left(\tau_{\mathrm{M}}\right)$ (see Table 


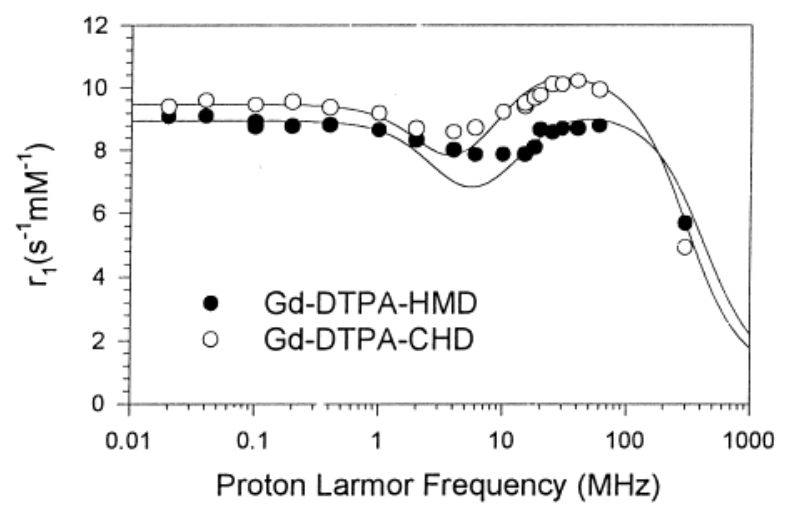

Figure 7. Longitudinal proton relaxivity of $\mathrm{Gd}(\mathrm{DTPA}-\mathrm{HMD})$ $(0.45 \mathrm{mM})$ and $\mathrm{Gd}(\mathrm{DTPA}-\mathrm{CHD})(0.424 \mathrm{mM})$ at $310 \mathrm{~K}$.

Table 4. Parameters Obtained from the Fitting of the Proton NMRD Data Obtained at $310 \mathrm{~K}^{\mathrm{a}}$

\begin{tabular}{lcccc}
\hline & $\begin{array}{c}\tau_{\mathrm{SO}} \\
(\mathrm{ps})^{\mathrm{b}}\end{array}$ & $\begin{array}{c}\tau_{\mathrm{V}} \\
(\mathrm{ps})^{\mathrm{c}}\end{array}$ & $\begin{array}{c}\tau_{\mathrm{R}} \\
(\mathrm{ps})^{\mathrm{d}}\end{array}$ & $\begin{array}{c}\tau_{\mathrm{M}} \\
(\mu \mathrm{s})^{\mathrm{e}}\end{array}$ \\
\hline Gd(DTPA-HMD) & 120 & 21 & 580 & 1.33 \\
Gd(DTPA-CHD) & 140 & 32 & 997 & 1.45
\end{tabular}

a The following parameters were fixed: the distance between $\mathrm{Gd}^{3+}$ and the inner-sphere water proton $(r=0.31 \mathrm{~nm})$, the distance of closest approach ( $\mathrm{d}=0.36 \mathrm{~nm})$, the relative diffusion constant $\left(D=3.5 \times 10^{-9} \mathrm{~m}^{2} \mathrm{~s}^{-1}\right)$ and the number of inner-sphere water molecules $(q=1) .{ }^{a} \tau_{\text {so }}=$ electronic relaxation time at low field. ${ }^{\mathrm{b}} \tau_{\mathrm{V}}=$ correlation time modulating the electronic relaxation. ${ }^{\mathrm{c}} \tau_{\mathrm{R}}$ $=$ rotational correlation time. ${ }^{\mathrm{d}} \tau_{\mathrm{M}}=$ residence time of the innersphere water molecule.

4) are comparable to those reported by Toth et al. (27) (from this publication, a $\tau_{\mathrm{M}}$ value of $1.03 \mathrm{~ms}$ can be calculated at $310 \mathrm{~K}$ for the compound with $\mathrm{n}=6$ ). The observed constancy of $\tau_{\mathrm{M}}$ is in line with the general observation that derivatization has hardly any effect on the water exchange rate of bisamides, which limit the relaxivity values. The main difference between both compounds is the rotational correlation time, which is longer for Gd(DTPA-CHD) than for Gd(DPTA-HMD). The $\tau_{R}$ values obtained by the fitting of the proton NMRD curves are shorter than those expected for such polymers and are indicative of internal motion. Therefore, the unexpectedly low relaxivity of these polymers can be explained by their relatively short $\tau_{\mathrm{R}}$ and the long residence time of their innersphere water molecules.

The present results show that introducing short, conformationally rigid DTPA-linking moieties does not pre vent the fast local motions in the extended polymeric chain, which dominate $\tau_{\mathrm{R}}$ and keeps the relaxivity low. Other studies with this type of DTPA copolymers, containing as linking units long hydrophilic poly(ethyleneglycol) (PEG) (40), or hydrophobic alkyl chains with a varying number $(n)$ of methylenes (29), showed that higher relaxivities were obtained only for long hydrophobic chains with $n \geq 10$. For these polymers, hydrophobic interactions between different chains lead to intramolecular aggregates and the formation of more rigid compact, globular structures, with slower local motions and global rotation, leading to higher relaxivity $(27,29)$. Studies with other polymeric carriers $(15,16)$ have also shown that higher relaxivities are obtained for more rigid compact, globular structures, for example by increasing the degree of substitution of the carrier.

The results of pharmacokinetic studies of the two polymeric compounds Gd(DTPA-HMD) and Gd(DTPA$\mathrm{CHD}$ ) injected in Wistar rats are shown in Figure 8. This shows that both compounds exhibit a fast exponential clearance from the blood. With a blood half-life shorter



Figure 8. Pharmacokinetics of Gd(DTPA-HMD) and Gd(DTPA-CHD) in Wistar rats.

than $10 \mathrm{~min}$, they show the same pharmacokinetic behavior as Gd(DTPA) ${ }^{2-}$, the extravascular/extracellular parent molecule.

\section{CONCLUSIONS}

We have obtained two main chain DTPA polymers by copolymerization of DTPA with two diamines of different structures and internal flexibilities. Despite the derivatization of two terminal carboxylate groups of each DTPA residue, with a somewhat reduced $\mathrm{Gd}^{3+}$ binding ability of the resulting amide moieties, the stability of the polymeric complexes should still be high enough to be used in vivo. This is supported by the observation that the reduced thermodynamic stability of small $\mathrm{Gd}^{3+}$ chelates of DTPA-bis amides relative to Gd(DTPA) ${ }^{2-}$ is compensated by their comparable or even favorable conditional stability constants and selectivity factors for $\mathrm{Gd}^{3+}$ relative to other biologically relevant cations such as $\mathrm{Zn}^{2+}$, leading to nonincreased in vivo dissociation of $\mathrm{Gd}^{3+}(31,41,42)$.

The $\mathrm{Gd}^{3+}$ complexes of the two polymers were obtained with $\mathrm{Gd}^{3+}$ yields of about 80 and $70 \%$ for $\mathrm{Gd}$ (DTPA-CHD) and Gd(DTPA-HMD), respectively, as measured by ICP. Solvent water ${ }^{17} \mathrm{O}$ NMR shift monitoring of titration experiments of the polymers with solid $\mathrm{GdCl}_{3}$ gave comparable results. The incomplete loading of the polymers with $\mathrm{Gd}^{3+}$, resulting in the presence of ca. $20-30 \%$ of uncomplexed, negatively charged DTPA units, while increasing their solubility and SEC-determined apparent molecular weights due to the negative charges present, will al so contribute to an increased internal mobility and reduced relaxivities.

The $\mathrm{Gd}^{3+}$ macromolecular complexes show somewhat higher relaxivities than the small parent $\mathrm{Gd}^{3+}$ chelate, Gd(DTPA) ${ }^{2-}$. The rigidity of the cyclic diamide linking moiety did improve the relaxivity of the complexes in water, but not as much as expected. This may result from the short length of the linking groups, which prevents the hydrophobic interaction between polymeric chains and the formation of a compact polymer, as happens with similar polymers with longer chains in the linking groups (29). A substantial residual flexibility of those polymers may still be present. Alternatively, the local motions located at the linking groups in the polymer chains might be less important than those of the DTPA moieties in 
determining the correlation time of the water molecule bound to the $\mathrm{Gd}^{3+}$ ion.

The rotational correlation time is longer for Gd(DTPA$\mathrm{CHD}$ ) than for Gd(DPTA-HMD), indicating a substantial decrease of the residual flexibility of the first polymer. However, the rotational correlation times obtained for these polymers are shorter than expected, indicating that internal motion is present. The low relaxivity of these polymers can thus be explained by their relatively short $\tau_{\mathrm{R}}$ and the long residence time of the inner-sphere water molecule.

With a blood half-life shorter than 10 min., both compounds exhibit the same pharmacokinetic behavior as Gd(DTPA) ${ }^{2-}$, the extravascular/extracellular parent molecule. Molecules with molecular weights lower than about $15 \mathrm{kDa}$ pass freely through glomerular filtration in the kidneys. Large size polymers are usually cleared slowly from the blood because of a restricted glomerular filtration. However, the clearance has to be related not only to the molecular weight of the product but also to its spatial conformation. In the present case, the polymers are made of linear and flexible chains and are characterized by a molecular weight not large enough to prevent the glomerular filtration. Thus, although the polymers are stable in vivo for the short time they stay in circulation, the fast excretion properties severely restrict the applicability of this type of $\mathrm{Gd}^{3+}$ polymeric complexes as MRA contrast agents.

\section{ACKNOWLEDGMENT}

The authors thank Dr. Sophie Laurent and Mrs Corinne Piérart for their help in recording the relaxometric data. This work was supported by F.C.T., Portugal, through the Praxis XXI Project 2/2.2/SAU/1194/95 and the Grant BD/5056795 to M. G. Duarte, by the ARC Program 95/00-194 of the French Community of Belgium, the F onds National de la Recherche Scientifique (FNRS) of Belgium and the E.U. Biomed II (MACE) project. This project was carried out within the framework of COST D8 and COST D18 E.U. programs.

\section{LITERATURE CITED}

(1) Lauffer, R. B. (1987) Paramagnetic metal complexes as water proton relaxation agents for NMR imaging. Chem. Rev. 87 (5), 901-927.

(2) Peters, J. A., Huskens, J ., and Raber, D. J . (1996) Lanthanide induced shifts and relaxation rate enhacements. Prog. Magn. Reson. Spectrosc. 28 (3/4), 283-350.

(3) Aime, S., Botta, M., Fasano, M., and Terreno, E. (1998) Lanthanide (III) chelates for NMR biomedical applications. Chem. Soc. Rev. 27 (1), 19-29.

(4) Caravan, P., Ellison, J . J ., McM urry, T. J ., and Lauffer, R. B. (1999) Gadolinium (III) chelates as MRI contrast agents: Structure, dynamics and applications. Chem. Rev. 99 (9), 2293-2352.

(5) Vander Elst, L., Maton, F., Laurent, S., Seghi, F., Chapelle, F., and Muller, R. N. (1997) A multinudear MR study of GdEOB-DTPA: comprehensive preclinical characterization of an organ specific MRI contrast agent. Magn Reson Med. 38 (4),604-14.

(6) Muller, R. N., Radüchel, B., Laurent, S., Platzek, J ., Piérart, C., Mareski, P., and Vander Elst, L. (1999) Physicochemical Characterization of MS-325, a New Gadolinium Complex, by Multinudear Relaxometry. Eur. J . Inorg. Chem. 1949-1955.

(7) Armitage, F. E., Richardson, D. E., and Li, K. C. P. (1990) Polymeric contrast agents for magnetic resonance imaging. Synthesis and characterization of gadolinium diethylenetriaminepentaacetic acid conjugated to polysaccharides. Bioconjugate Chem. 1 (6), 365-374.
(8) Meyer, D., Schaefer, M., Bouillot, A., Beaute, S., and Chambon, C. (1991) Paramagnetic dextrans as magnetic resonance contrast agents. Invest. Radiol. 26, S50-52.

(9) Rongved, P., and Klaveness, J . (1991) Water-soluble polysaccharides as carriers of paramagnetic contrast agents for magnetic resonance imaging: Synthesis and relaxation properties. Carbohydr. Res. 214, 315-323.

(10) Rongved, P., Lindberg, B ., and Klaveness, J . (1991) Crosslinked, degradable starch microspheres as carriers of paramagnetic contrast agents for magnetic resonance imaging: Synthesis, degradation and relaxation properties. Carbohydr. Res. 214, 325-330.

(11) Rongved, P., Fritzell, T. H., Strande, P., and Klaveness, J . (1996) Polysaccharides as carriers for magnetic resonance imaging contrast agents: synthesis and stability of a new amino acid linker derivative. Carbohydr. Res. 287, 77-89.

(12) Corot, C., Schaefer, M., Beauté, S., Bourrinet, P., Zehaf, S., Bénizé, V., Sabatou, M., and Meyer, D. (1997) Physical, chemical and biological evaluations of CMD-A2-Gd-DOTA. Acta Radiol. 38 (S412), 91-99.

(13) Rebizak, R., Schaefer, M., and Dellacherie, E. (1997) Polymeric conjugates of $\mathrm{Gd}^{3+}$ diethylenetriamine pentaacetic acid and dextran 1 . Synthesis, characterization and paramagnetic properties. Bioconjugate Chem. 8(4), 605-610.

(14) Rebizak, R., Schaefer, M., and Dellacherie, E. (1998) Polymeric conjugates of $\mathrm{Gd}^{3+}$ diethylenetriamine pentaacetic acid and dextran 2. Influence of spacer arm length and conjugate molecular mass on the paramagnetic properties and some biological parameters. Bioconjugate Chem. 9, 94-99.

(15) Rebizak, R., Schaefer, M., and Dellacherie, E. (1999) Macromolecular contrast agents for magnetic resonance imaging. Influence of polymer content in ligand on the paramagnetic properties, Eur. J . Pharm. Sci. 7, 243-248.

(16) Corsi, D. M., Vander Elst L., Muller, R. N., Peters, J . A., and van Bekkum, H. (2000) Inulin as carrier for contrast agents in magnetic resonance imaging. Chem. Eur. J. (in press).

(17) Lauffer, R. B., and Brady, T. J . (1985) Preparation and water relaxation properties of proteins labeled with paramagnetic metal chelates. Magn. Reson. I maging 3 (1), 1116.

(18) Schmiedel, U., Ogan, M., Paajanen, H., Marotti, M., Crooks, L. E., Brito, A. C., and Brash, R. C. (1987) Albumin labeled with gadolinium-DTPA as an intravascular blood pool enhancing agent for MR imaging: biodistribution and imaging studies. Radiology, 162 (1), 205-210.

(19) Fossheim, S. L., Kellar, K. E., Månsson, S., Colet, 」. M., Rongved, P., Fahlvik, A. K., and Klaveness, J . (1999) Investigation of lanthanide-based starch partides as a model system for liver contrast agents. J . Magn. Reson. Imaging 9, 295-303.

(20) Sieving, P. F., Watson, A. D., and Rocklage, S. M. (1990) Preparation and characterization of paramagnetic polychelates and their protein conjugates. Bioconjugate Chem. 1,6571.

(21) Schuhmann-Giampieri, G., Schmitt-Willich, H., Frenzel, T., Press, W. R., and Weinmann H. J . (1991) In vivo and in vitro evaluation do Gd-DTPA-polylysine as a macromolecular contrast agent for magnetic resonance imaging. Invest. Radiol. 26 (11), 969-974.

(22) Spanoghe, M., Lanens, D., Dommisse, R., Van der Linden, A., and Alderweireldt, F. (1992) Proton relaxation enhancement by means of serum albumin and poly-lysinelabeled with DTPA-Gd ${ }^{3+}$ : relaxivities as a function of molecular weight and conjugation efficiency. Magn. Reson. I maging 10 (6), 913917.

(23) Desser, T. S., Rubin, D. L., Muller, H. H., Qing, F., Khodor, S., Zanazzi, G., Young, S. W., Ladd, D. L., Wellons, J. A., Kellar, K. E., Toner, J., and Snow, R. (1994) Dynamics of tumor imaging with Gd-DTPA-poly(ethylene glycol) polymers: dependence on molecular weight. J. Magn. Reson. Imaging 4 (3), 467-472.

(24) Frank, H., Weissleder, R., Bogdanov, A., and Brady, T. (1994) Detection of pulmonary emboli by using MR angiography with MPEG-PL-GdDTPA: an experimental study in rabbits. A. J . R. Am. J . Roentgenol. 162 (5), 1041-1046. 
(25) Aime, S., Botta, M., Crich, S. G., Giovenzana, G., Palmisano, G., and Sisti, M. (1999) Novel paramagnetic macromolecular complexes derived from the linkage of a macrocyclic $\mathrm{Gd}(\mathrm{III})$ complex to polyamino acids through a squaric acid moiety. Bioconjugate Chem. 10, 192-199.

(26) Bryant, L. H.J r., Brechbiel, M. W., Wu, C., Bulte, J . W.M., Herynek, V., and Frank J. A. (1999) Synthesis and relaxometry of high-generation ( $\mathrm{G}=5,7,9$ and 10$)$ PAMAM dendrimerDOTA-gadol inium chelates. J . Magn. Reson. Imaging 9 (2), 348-352.

(27) Tóth, E., Helm, L., Kellar, K. E., Merbach, A. E. (1999) Gd(DTPA-bisamide)alkyl copolymers: a hint for the formation of MRI contrast agents with very high relaxivity. Chem Eur. J . 5 (4), 1202-1211.

(28) Montembault, V., Soutif, J .-C., and Brosse, J .-C. (1996) Synthesis of chelating molecules as agents for magnetic resonance imaging, 3. Polycondensation of diethyletriamine pentaacetic acid bisanhydride with diols and diamines. React. Funct. Polym. 29, 29-39.

(29) Kellar, K. E., Henrichs, P. M., Hollister, R., Koenig, S. H., Eck, J., and Wei, D. (1997) High relaxivity linear Gd(DTPA)polymer conjugates: the role of hydrophobic interactions. Magn. Reson. Med. 38, 712-716.

(30) Krejcarek, G. E., and Tucker, K. L. (1977) Covalent attachment of chelating groups to macromolecules Biochem. Biophys. Res. Commun. 77, 581-585.

(31) Geraldes, C. F. G. C., Urbano, A. M., Alpoim, M. C., Sherry, A. D., Kuan, K.-T., Rajagopalan, R., Maton, F., and Muller, R. N. (1995) Preparation, physicochemical characterization, and relaxometry studies of various gadolinium(III)-DTPAbis(amide) derivatives as potential magnetic resonance contrast agents. Magn. Reson. I maging 13 (3), 401-420.

(32) Muller, R. N., Dedercq, D., Vallet, P., Giberto, F., Daminet, B., Fischer, H. W., Maton, F., and Van Haverbeke, Y. (1990) I mplementation and operation of an integrated and comprehensive relaxometric data bank, Proc. ESMRMB, 7th Annual Congress, Strasbourg, p 394

(33) Vallet, P. (1992) Re axi vity of nitroxi destable freeradicals. Evaluation by field cycling method and optimisation, Ph.D. Thesis, University of Mons-Hainaut, Belgium.
(34) Geraldes, C. F. G. C., Delgado, R., Urbano, A. M., Costa, J ., J anasada, F., and Nepveu, F. (1995) Complexes of $\mathrm{Ga}^{3+}$ and $\mathrm{In}^{3+}$ with the $\mathrm{N}, \mathrm{N}^{\prime}$-bis(butylamide) derivative of diethylenetriaminepentaacetic acid: stability constants and nudear magnetic resonance studies in aqueous solution, J . Chem. Soc., Dalton Trans. 327-335.

(35) Levine, Y. K., Birdsall, N. J . M., Lee, A. G., Metcalfe, J . C., Partington, P., and Roberts G. C. K. (1974) Calculation of dipolar magnetic relaxation times in molecules with multiple internal rotations: II. Theorethical results for anisotropic overall motion of the molecule, and comparison with carbon-13 relaxation times in n-alkenes and n-alkyl bromides. J. Chem. Phys. 60 (7), 2890-2899.

(36) Mason, J. (1987) Multinuclear NMR, pp 142-143 Plenum Press, New York.

(37) Freed, J . H. (1978) Dynamic effects of pair correlation functions on spin relaxation by translational diffusion in liquids. II. Finite jumps and independent $\mathrm{T}_{1}$ processes. J . Chem. Phys. 68, 4034-4037.

(38) Solomon, I. (1955) Relaxation processes in a system of two spins. Phys. Rev. 99, 559-565.

(39) Bloembergen, N. (1957) Proton relaxation times in paramagnetic solutions, J. Chem. Phys. 27, 572-573.

(40) Tóth, E., Van Uffelen, I., Helm, L., Merbach, A. E., Ladd, D., Briley-Saebo, K., and Kellar, K. E. (1998) Gadoliniumbased linear polymer with temperature-independent proton relaxivities: a unique interplay between the water exchange and rotational contributions. Magn. Reson. Chem. 36, S125S134.

(41) Sherry, A. D., Cacheris, W. P., and Kuan, K.-T- (1988) Stability constants for $\mathrm{Gd}^{3+}$ binding to model DTPA-conjugates and DTPA-proteins: Implications for their use as magnetic resonance contrast agents. Magn. Reson. Med. 8 , 180-190.

(42) Cacheris, W. P., Quay, S. C., and Rocklage, S. M. (1990) The relationship between thermodynamics and the toxicity of gadolinium complexes. Magn. Reson. I maging 8, 467-481. BC000065R 